\title{
Hydrogen Induced C-C, C-N, and C-S Bond Activation on Pt and Ni Surfaces
}

\author{
Professor John L Gland, \\ Chemistry Department, The University of Michigan \\ Ann Arbor, Michigan, 48109
}

DOE/ER/14190--1

DE93 004647

In the first year of this program our work has focussed on hydrogen induced bond activation in adsorbed organic molecules and intermediates containing C-S and C-N and $\mathrm{C}-\mathrm{C}$ bonds on the $\mathrm{Ni}(100), \mathrm{Ni}(111)$ and $\mathrm{Pt}(111)$ single crysta! surfaces. Simple surfaces like (111) and (100) have been selected so that the surface reactions kinetics for a single dominant bonding type can be studied. These studies have included both low pressure hydrogenolysis studies using TPD and vacuum spectroscopies, and in-situ synchrotron based soft X-ray hydrogenolysis studies in the 0.01 torr range. Considerable effort has been focussed on extension of Fluorescence Yield Near Edge Spectroscopy (FYNES) above the carbon $\mathrm{K}$ edge for characterizing adsorbed organic reactants and for in-situ kinetic studies of bond activation. In collaboration with the chemistry Department of Brookhaven National Laboratory we have designed and assembled a state of the art end station equipped with improved facilities for in-situ FYNES kinetics studies. Our studies of $\mathrm{H}$ induced $\mathrm{C}-\mathrm{S}$ bond activation on the $\mathrm{Pt}(111)$ surface are developing well, papers are being prepared and a publication is in press. Several initial series of vacuum based reactivity experiments have also been performed to probe hydrogen induced C-S, $\mathrm{C}-\mathrm{N}$ and $\mathrm{C}-\mathrm{C}$ bond activation in simple organic species on the $\mathrm{Ni}(100)$ and $\mathrm{Ni}(111)$ surfaces. These experiments indicate that hydrogen induced bond activation is enhanced on $\mathrm{Ni}$ relative to $\mathrm{Pt}$. Several simple hydrogen induced reaction channels have been identified using isotopic hydogenolysis studies. These reaction channels are currently being characterized in more detail using surface spectroscopies and detailed kinetic studies. The hydrogen induced bond activation in simple benzene derivatives appears to offer real opportunities for studying a range of analogous hydrogen induced processes on a series of analogous surfaces.

Substantial attention has been focussed on C-S bond activation in adsorbed methylthiolate on the $\operatorname{Pt}(111)$ surface since we obtained extremely promising initial results with this reaction system. A combination of temperature programmed reaction experiments and fluorescence yield near edge spectroscopy (FYNES) has been used to characterize hydrogen ind $\mathrm{d}$ C-S bond activation in adsorbed methylthiolate on the Pt(111) surface A low temperature methane peak observed at $310 \mathrm{~K}$ during temperature programmed decomposition of methanethiol cleaily involves reaction with adsorbed hydrogen since deuterium incorporation is observed in the presence of coadsorbed 
deuterium. Some multiple deuteration is observed suggesting that a mixture of carbon containing species may be involved in the hydrogenolysis process. In situ FYNES above the carbon $\mathrm{K}$ edge has been used to characterize the kinetics of this hydrogenolysis process in more detail. Transient FYNES measurements were used to characterize changes in the total carbon concentration during the hydrogenolysis reaction. In situ temperature programmed reaction experiments performed in 0.02 Torr of hydrogen clearly indicate that hydrogenolysis begins near $290 \mathrm{~K}$ and all carbon containing species are removed by $360 \mathrm{~K}$. In situ isothermal kinetic studies indicate that the hydrogenolysis reaction is first order in adsorbed thiolate coverage and approximately half order in hydrogen pressure. The apparent activation energy for the hydrogenolysis reaction is $18 \mathrm{kcal} / \mathrm{mol}$ in the presence of 0.02 Torr of gaseous hydrogen. This activation energy represents a lower bound for the hydrogenolysis activation energy since the apparent heat includes the heat of adsorption for hydrogen. These direct kinetic measurements of this hydrogenolysis reaction under reactive gaseous environments highlight the role that in situ FYNES can play in characterizing hydrogen induced bond activation on surfaces.

A second high temperature C-S bond activation channel is observed at $450 \mathrm{~K}$ for adsorbed methylthiolate. This high temperature channel does not involve reaction with "free" adsorbed hydrogen since hydrogen is completely desorbed well below this temperature. This is confirmed by the observation that we observe no significant incorporation of coadsorbed isotopic hydrogen into the methane product. Instead hydrogenolysis occurs through hydrogen transfer between coadsorbed intermediate producing methane. Transfer of $\mathrm{CH}_{\mathrm{X}}(\mathrm{x}=2$ ?) groups between coadsorbed intermediates also produces produces $\mathrm{C}_{2} \mathrm{H}_{4}$ at $450 \mathrm{~K}$. reaction of coadsorbed perdeutro and perhydro methanethiol produces a statistical distribution of deuterated methane, and a statistical distribution of deuterated ethylene. These isotopic studies suggest either: 1) substantial isotopic exchange occurs between intermediates prior to $\mathrm{C}-\mathrm{S}$ bond activation, or 2) sequential transfer of single hydrogens are involved

$\mathrm{C}-\mathrm{N}$ bond hydrogenolysis is more difficult to initiate than $\mathrm{C}-\mathrm{S}$ bond activation, however coadsorbed hydrogen clearly enhances $\mathrm{C}-\mathrm{N}$ bond activation for adsorbed methylamine on the $\mathrm{Pt}(111)$ surface. Initial studies indicate that the $\mathrm{C}-\mathrm{N}$ bond in $\mathrm{T}$ butylamine is more easily activated than $\mathrm{C}-\mathrm{N}$ bonds in primary amines. hydrogenolysis studies of phenylamine on the $\operatorname{Pt}(111)$ surface suggests that the ammonia formation channel may provide an opportunity for detailed kinetic characterization using in-situ methods. Studies of toluene hydrogenolysis on the Ni(111) surface are currently in nrogress.

Substantial improvements have been installed on our surface science àp̄paratutius here at the University of Michigan. Components for a atmospheric pressure reactor system 
with facilities for UHV sample transfer have been purchased. The reactor system has been assembled and is now being tested prior to installation on our surface science system. Our vibrational EELS system has been installed, and is now fully operational. several components have been purchased to upgrade the productivity of the "classical" surface science methods.

As indicated in the first paragraph, we have focussed considerable effort on design and development of new facilities for FYNES as part of the development of a new surface science end station at Brookhaven National Laboratory. This end station is a collaborative effort with Dr. J Hrbek of the Chemistry department at Brookhaven National Laboratory. The end station has been assembled and the facilities are being tested.

\section{Publications}

T. S. Rufael, J. Prasad, D. A. Fischer, and J. L. Gland, "Hydrogenolysis of Adsorbed Methylthiolate on the $\mathrm{Pt}(111)$ Surface", Surface Science (1992) in press.

\section{Manuscripts in Preparation}

T. Rufael, J. L Gland, R. J. Koestner, E. B. Kollin and M. Salmeron, "Adsorption and Reactions of Methanethiol on Pt(111) Surfaces"

T. Rufael and J. L. Gland, " High Temperature Hydrogenolysis of Methanethiolate on the $\operatorname{Pt}(111)$ Surface",

\section{DISCLAIMER}

This report was prepared as an account of work sponsored by an agency of the United States Government. Neither the United States Government nor any agency thereof, nor any of their employees, makes any warranty, express or implied, or assumes any legal liability or responsibility for the accuracy, completeness, or usefulness of any information, apparatus, product, or process disclosed, or represents that its use would not infringe privately owned rights. Reference herein to any specific commercial product, process, or service by trade name, trademark, manufacturer, or otherwise does not necessarily constitute or imply its endorsernent, recommendation, or favoring by the United States Government or any agency thereof. The views and opinions of authors expressed herein do not necessarily state or reflect those of the United States Government or any agency thereof. 
DATE FILMED 01108193 
政 